\title{
Theoretical Study of the [4+2] Cycloaddition Reaction of Trifluoroethylene with Five-membered Chalcogens Heterocyclic Compounds
}

\author{
Haydar A. Mohammad-Salim ${ }^{1}$ and Hassan H. Abdallah ${ }^{2}$ \\ ${ }^{1}$ Department of Chemistry, Faculty of Science, University of Zakho, \\ Duhok 42001, Iraq \\ ${ }^{2}$ Department of Chemistry, College of Education, Salahaddin University, \\ Erbil 44001, Iraq
}

\begin{abstract}
- $[4+2]$ cycloaddition reaction has enormous significant in organic chemistry synthesis reactions and yet remains unexplored for the synthesis of fluorine-containing compounds. A density functional theory study of the stereo- and regioselectivity of the [4+2] cycloaddition reaction of trifluoroethylene with furan, thiophene, and selenophene was carried out in the gas phase. The B3LYP functional is used throughout in combination with 6-31G(d) basis set. The analysis of stationary points and the energetic parameters indicates that the reaction mechanism is concerted and confirms that the exo-adducts are thermodynamically and kinetically more favored than endo-adducts. The calculated branching ratio indicates that the exo-adducts have the higher percent yield than endoadducts and the yield of endo-adducts is increased only slightly on proceeding from furan, through thiophene, and onto selenophene. The analysis of the frontier molecular highest occupied molecular orbital (MO) and lowest unoccupied MO orbitals indicates that the exo-adducts are more stable due to their higher energy gab. The reaction energies were compared to the MP2/6-31G(d) and CCSD(T)/6-31G(d) calculations.
\end{abstract}

Index Terms - Density functional theory, B3LYP, Regioselectivity, Stereoselectivity, [4+2] Cycloaddition.

\section{INTRODUCTION}

The [4+2] cycloaddition reaction (Diels-Alder reaction) is one of the most powerful reactions for building sixmembered carbocyclic ring in organic synthesis (Nicolaou, et al., 2002). The Diels-Alder reaction of conjugated diene with dienophile (alkene or alkyne) is concerted reaction (Houk, et al., 1986; Woodward and Katz, 1959). This reaction proceeds more favorable if electron-rich dienes reacts with

\section{ARO-The Scientific Journal of Koya University}

Volume VII, No.2 (2019), Article ID: ARO.10575, 9 pages

DOI: $10.14500 /$ aro. 10575

Received 22 October 2019; Accepted 16 December 2019

Regular research paper: Published 28 December 2019

Corresponding author's e-mail: hayder.salim@uoz.edu.krd

Copyright (C) 2019 Haydar A. Mohammad-Salim and

Hassan H. Abdallah. This is an open-access article distributed under the Creative Commons Attribution License. electron-poor dienophile. Thus, typical dienes are substituted with electron-donating groups whereas good dienophiles are substituted with electron-withdrawing groups (Gregoritza and Brandl, 2015).

The Diels-Alder reaction may give two stereoisomeric products, exo- and endo-adducts, relying on the conformation of the transition state when a cyclic diene and dienophile react with each other (Lautens and Edwards, 1989; Nickon, et al., 1978). For that reason, a huge amount of theoretical studies have been devoted trying to explore the reaction mechanism leading to exo- and endo-selectivity. Density functional theory (DFT) has been used widely and found as a very convenient method for getting reliable results and it has low computational cost (Cossío, et al., 1999; Liu, et al., 1998; Silva and Goodman, 2002). This method has been successfully used in many [4+2] cycloaddition reactions (Domingo, et al., 2002; Domingo, et al., 2014; Fernández and Bickelhaupt, 2014; Ho, et al., 2016; Levandowski, et al., 2018; Rivero, et al., 2017b). Among these studies, computational works were compared with experimental to obtain detailed reaction mechanism, stero- and regioselectivity. Stereoselectivity of the reaction of cyclopentadiene with protonated phenylethylimine was studied at B3LYP/6-31G(d) level of theory (Teixeira, et al., 2009). The results indicate that the exo-adduct is found to be more stable than endo-adduct. In addition, DFT method at M06-2X/6-31G(d) level of theory was used for the reaction of s-cis-2,3-dibromo-1,3-butadiene and malic anhydride (Rivero, et al., 2017a). This reaction clearly favors the exo-adduct over the endo-adduct due to the lower activation energy for the exo path.

Fluorine-containing organic compounds have found a significant position in organic chemistry and the synthesis of compounds exhibiting exciting properties for medicinal and agricultural purposes. The reaction of 2-fluorooct-1-en3 one with cyclopentadiene was studied experimentally and found to yield the exo-adduct preferably under thermal and microwave-assisted conditions (Essers, et al., 2002). The percent yield for exo- and endo-adducts was found to be 69 and 31\%, respectively, under thermal condition, whereas the percent yield became 70 and $30 \%$ under microwave- 
assisted condition. The reactions of cyclopentadiene with benzyl 2-fluoroacrylate, 2-fluoroacrylic acid amide, 1,1-difluoroethene, and 1,2-diflurodinitro ethene were studied experimentally and the exo-adducts were found to be more favorable with higher percent yield than endo-adducts (Baum, et al., 1991; Ito, et al., 1999; Ito, et al., 1998; Leroy, et al., 1987).

The Diels-Alder reaction of trifluoroethylene (TFE) with furan and its derivatives has been investigated experimentally (Chambers, et al., 2000). However, based on our knowledge, the detail information about the reaction mechanism, stereo- and regioselectivity have not yet been obtained. Therefore, the aim of this paper is to suggest the mechanism of the cycloaddition of TFE with furan and other heterocyclic compounds containing chalcogens using DFT method. Herein, furan, 2, thiophene, 3, and selenophene, 4 are used in [4+2] cycloaddition reaction with TFE, 1 to investigate the effect of chalcogens on reaction mechanism and regioselectivity. Scheme 1 shows the exo- and endoadducts of these [4+2] cycloaddition reactions.

\section{Computational Methods}

All calculations have been done with the Gaussian 9 package under Linux operation system (Frisch, et al., 2009). DFT method has been proven to be a convenient method for the study of [4+2] cycloaddition reactions and is achieved in this study (Khabashesku, et al., 2001; Lemal, 2017; Parr
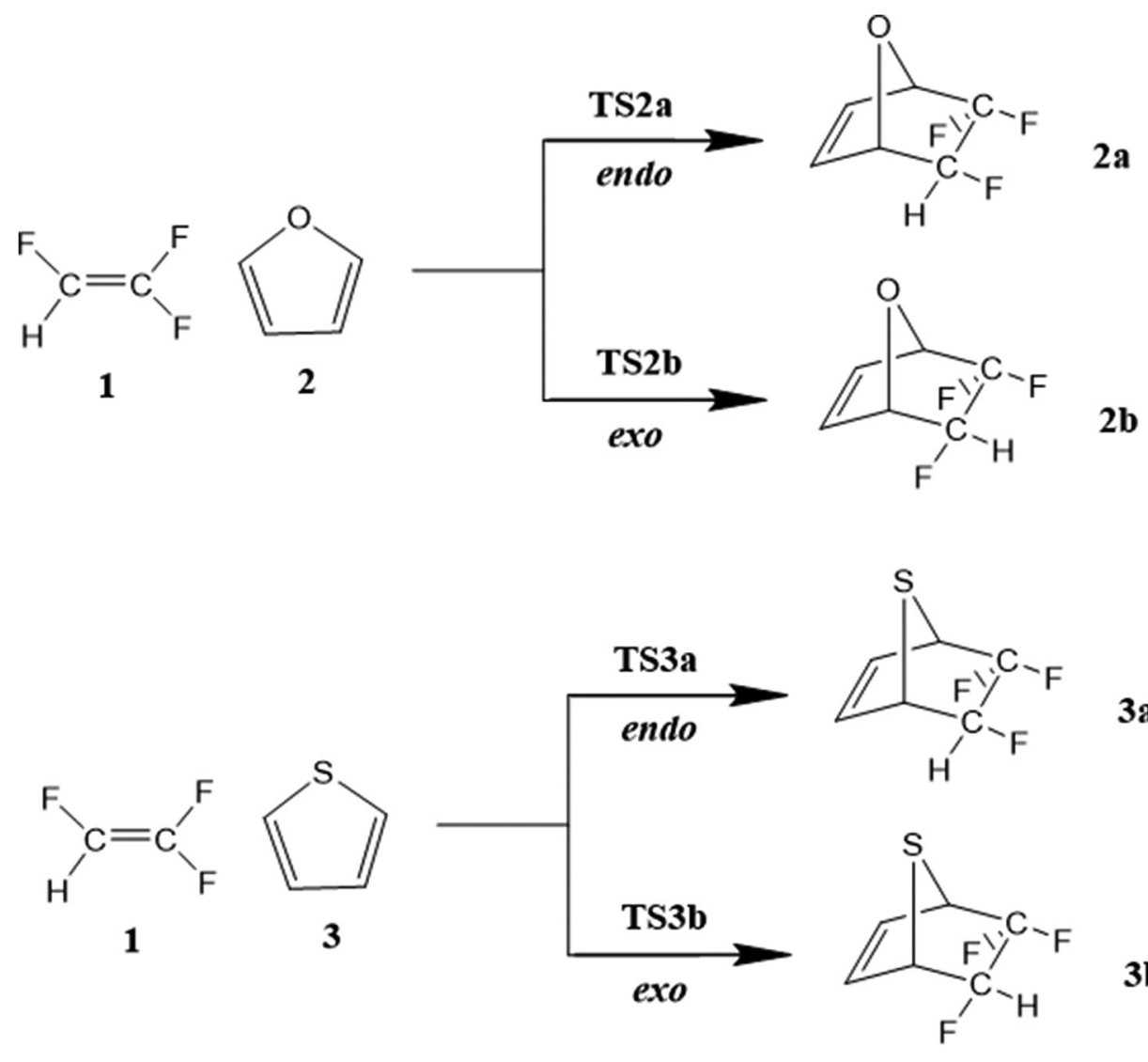

3b

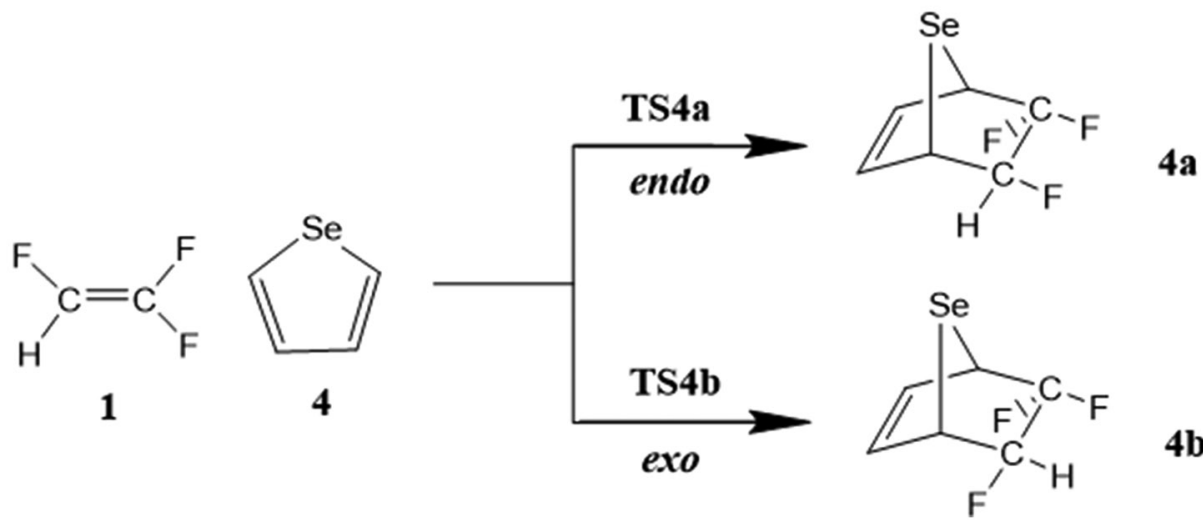

Scheme 1: Reaction paths for the [4+2] cycloaddition reaction of TFE, 1 with furan, 2, thiophene, 3, and selenophene, 4 . 
and Weitao, 1989). B3LYP functional is used throughout in combination with 6-31G(d) basis set (Ditchfield, et al., 1971; Lee, et al., 1988). MP2 and CCSD(T) methods were used to predict the reaction energies using the same basis set. Frequency calculations were performed to ensure that a transition state has only one imaginary frequency and a local minimum has no imaginary frequencies. Intrinsic reaction coordinate computations were carried out to verify that the transition states connect with the required reactants and products (Fukui, 1970). All energies and thermodynamic parameters reported in this paper were obtained from the frequency calculations at the same level of theory. The enthalpies, Gibbs free energies, and entropies in gas phase were obtained with the standard statistical thermodynamics at $298.15 \mathrm{~K}$ and $1 \mathrm{~atm}$. The CYLview software was used as a graphical interface (Legault, 2009).

The global electrophilicity index $(\omega)$ is obtained in terms of the electronic chemical potential $(\mu)$ and the chemical hardness $(\eta)$ using the following simple expression (Parr, et al., 1999):

$$
\omega=\frac{\mu^{2}}{2 \eta}
$$

The chemical hardness $(\eta)$ and the electronic chemical potential $(\mu)$ quantities may be approached in terms of the one-electron energies of highest occupied molecular orbital (HOMO) and lowest unoccupied MO (LUMO), $\varepsilon_{H}$ and, $\varepsilon_{L}$ as (Parr and Pearson, 1983; Parr and Weitao, 1994):

$$
\begin{gathered}
\eta \approx \varepsilon_{L}-\varepsilon_{H} \\
\mu \approx \frac{\varepsilon_{H}+\varepsilon_{L}}{2}
\end{gathered}
$$

The relative nucleophilicity index $(N)$ obtained based on the energies of HOMO within the scheme of Kohn-Sham (Kohn and Sham, 1965). This quantity can be defined using equation (4). Where TCE is tetracyanoethylene and is chosen due to its lowest HOMO energy as a reference (Domingo, et al., 2008).

$$
N=E_{H O M O(N u)}-E_{H O M O(T C E)}
$$

\section{ReSUlts AND Discussion}

In this study, B3LYP/6-31G(d) level of theory is used and transition states for the concerted reaction mechanism have been found. The stationary points analysis involved in the [4+2] cycloaddition reactions of TFE, 1 with furan, 2 , thiophene, 3 , and selenophene, 4 gave corresponding compound 2a, 2b, 3a, 3b, 4a, and $4 \mathrm{~b}$ and are sketched in Scheme 1. The relative electronic energies of the transition states and their corresponding products in the gas phase are presented in Figs. 1-3. As shown from these figures, the endo transition states (TS2a for TFE+furan, TS3a for TFE+thiophene, and TS4a for TFE+selenophene) are 1.45, 0.52 , and $0.1 \mathrm{kcal} / \mathrm{mol}$ higher than the exo transition states (TS2b for TFE+furan, TS3b for TFE+thiophene, and TS4b for TFE+selenophene), respectively.

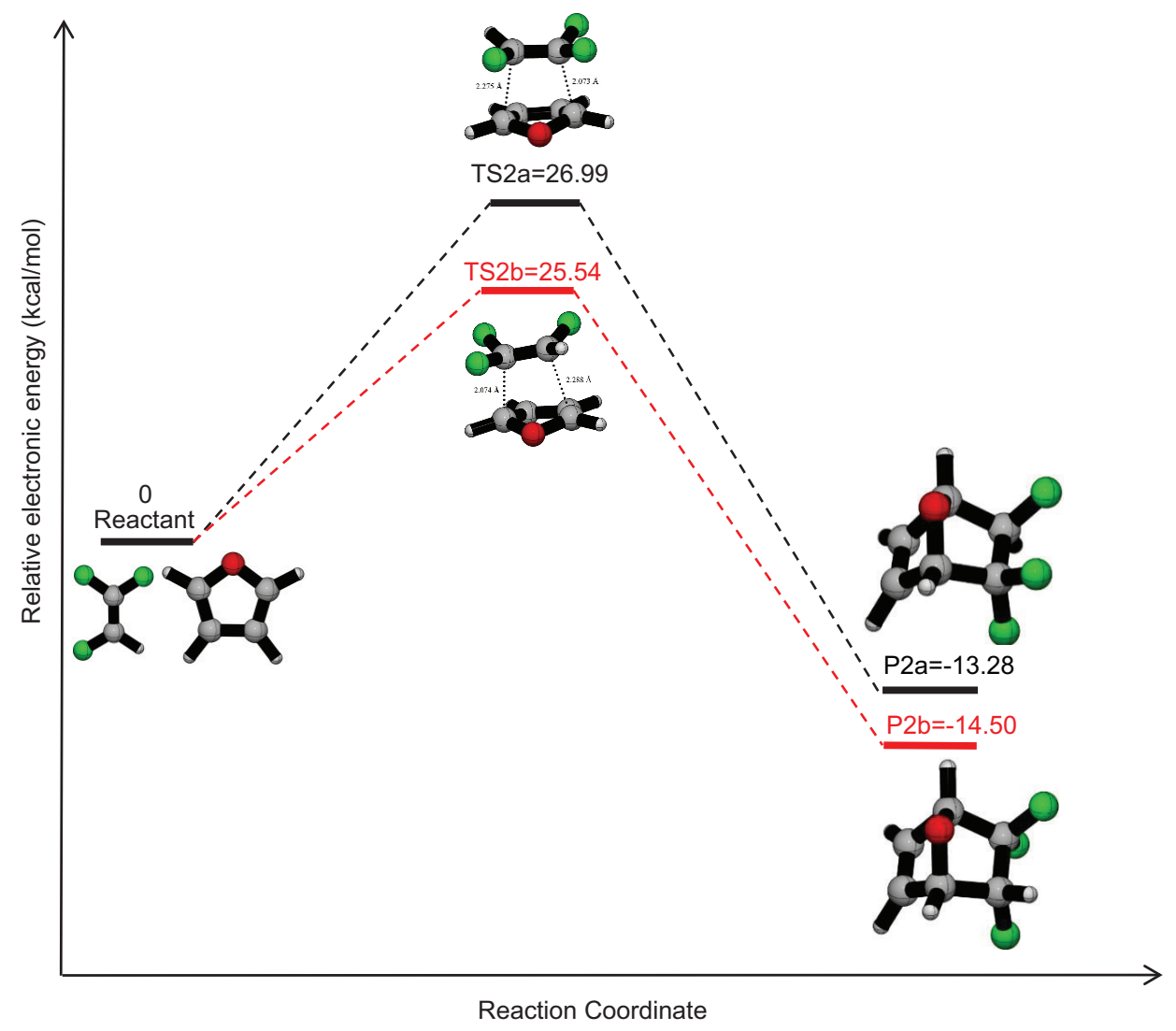

Fig. 1. Energy profile for the [4+2] cycloaddition reaction of trifluoroethylene with furan using B3LYP/6-31G(d) level of theory. The energies are given relative to reactants $(\mathrm{R})(\mathrm{kcal} / \mathrm{mol})$. 


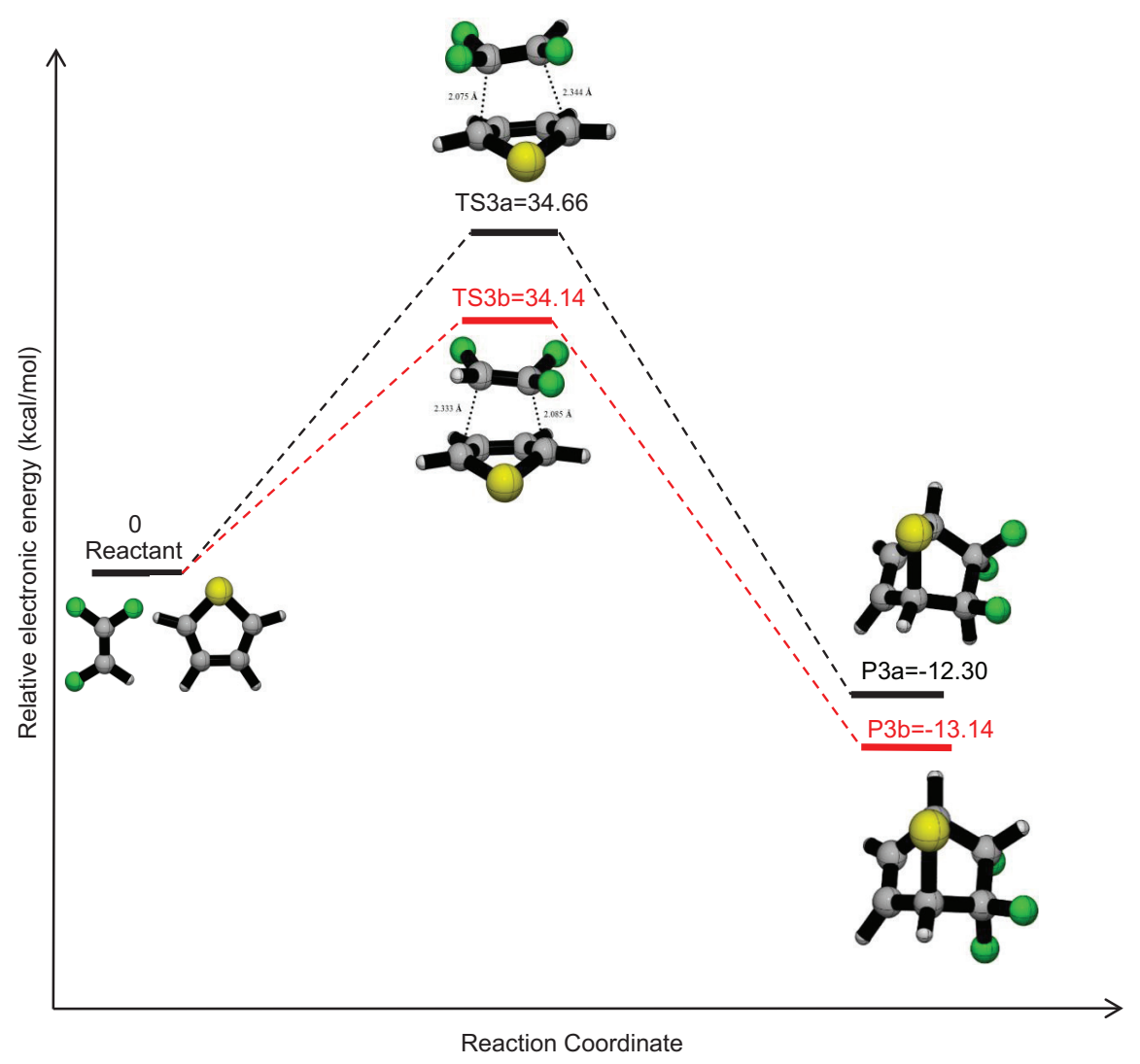

Fig. 2. Energy profile for the $[4+2]$ cycloaddition reaction of trifluoroethylene with thiophene using B3LYP/6-31G(d) level of theory. The energies are given relative to reactants $(\mathrm{kcal} / \mathrm{mol})$.

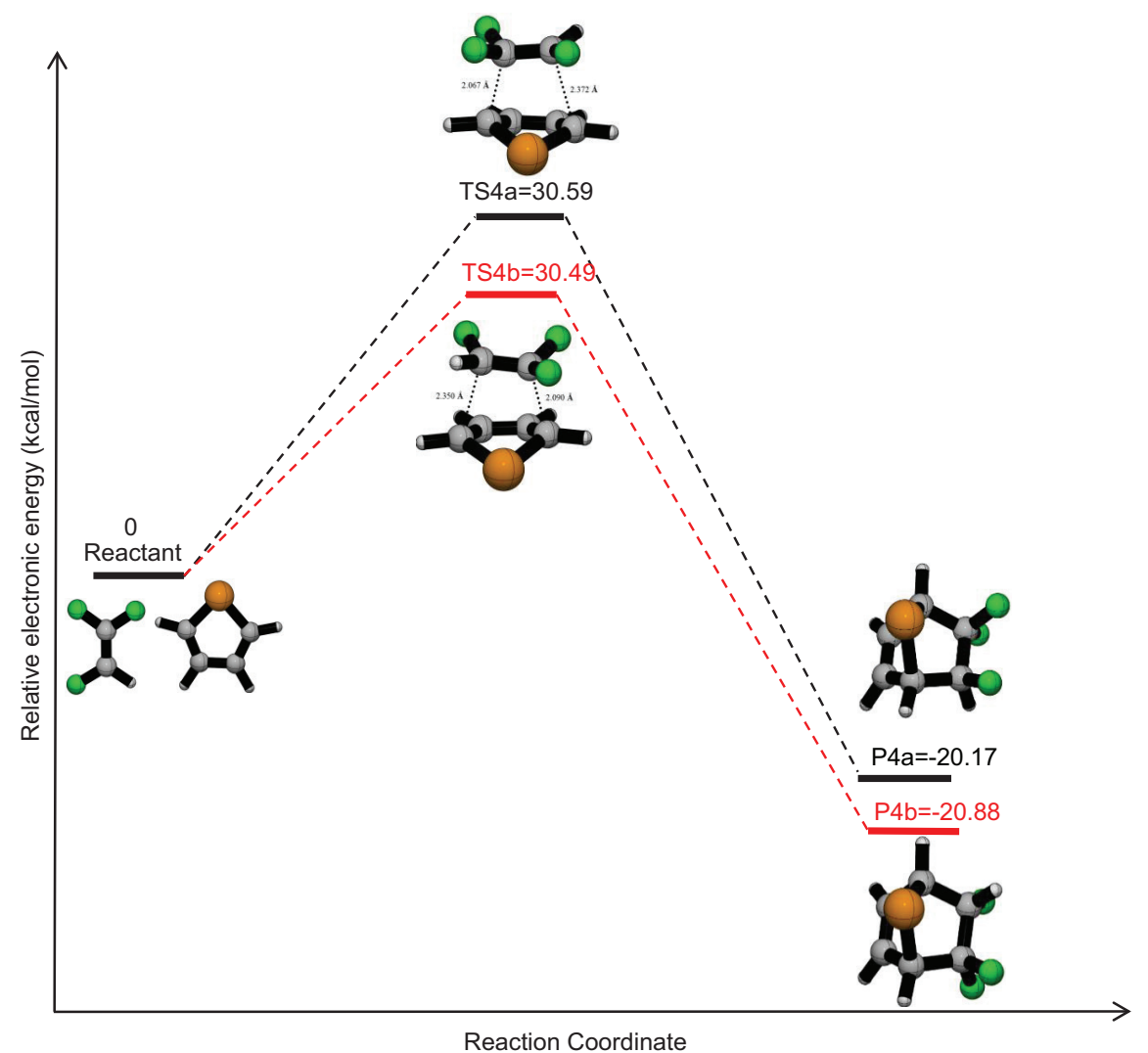

Fig. 3. Energy profile for the [4+2] cycloaddition reaction of trifluoroethylene with selenophene using B3LYP/6-31G(d) level of theory. The energies are given relative to reactants $(\mathrm{kcal} / \mathrm{mol})$. 


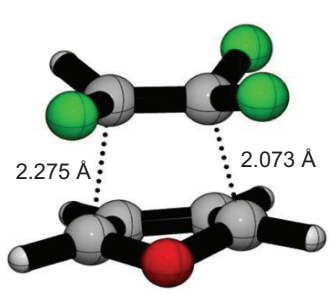

TS2a

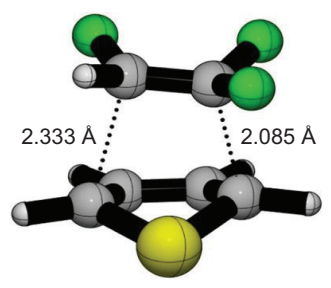

TS3b

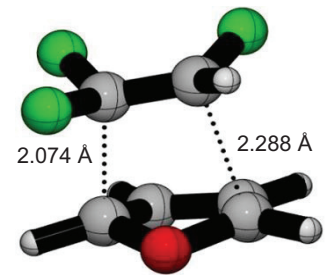

TS2b

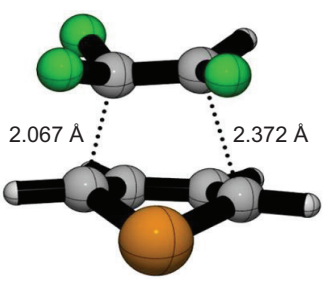

TS4a

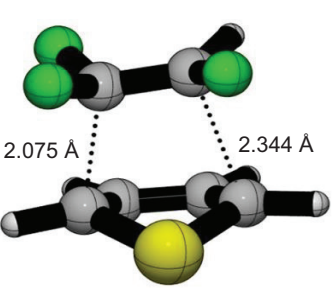

TS3a

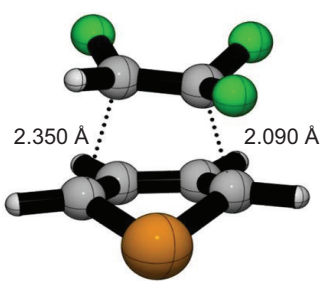

TS4b
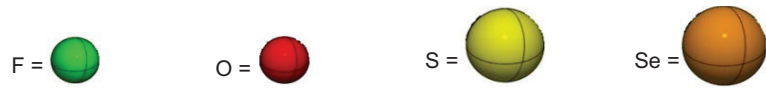

Fig. 4. Optimized geometries of the transition states involved in the [4+2] cycloaddition reactions of trifluoroethylene with furan, thiophene, and selenophene using B3LYP/6-31G(d) level of theory.

The activation energies for these [4+2] cycloaddition reactions are $26.99 \mathrm{kcal} / \mathrm{mol}$ for endo path and $25.54 \mathrm{kcal} /$ mol for exo path for the reaction with furan. For the reaction of TFE with thiophene, the activation energies for endo path are $34.66 \mathrm{kcal} / \mathrm{mol}$ and for exo path are $34.15 \mathrm{kcal} / \mathrm{mol}$. The activation energies for the reaction of TFE with selenophene are 30.58 and $30.49 \mathrm{kcal} / \mathrm{mol}$ for the endo and exo path, respectively. These results confirm that the exo reaction paths for three reactions are more favorable than endo reaction paths. Based on our knowledge, most of the studies of the exo- and endo-stereochemistry in the [4+2] cycloaddition reactions have shown that the exo-adduct is more stable thermodynamically whereas the endo-adduct is formed faster and kinetic control is observed (Cooley and Williams, 1997; Foster, et al., 2015; Hoffmann and Woodward, 1968; Lozynskyi, et al., 2016; Pavelyev, et al., 2016; Rulíšek, et al., 2005; Szalai, et al., 2007). However, in the current study, the exo-adduct is kinetically and thermodynamically more favorable than endo-adduct. Similar results were found for the [4+2] cycloaddition reaction of Zn-porphyrin trimer with butadiyne, nitroalkenes with methyl vinyl ether and intermolecular cycloaddition reaction of (Z)-1-(2-iodo-3phenylprop- 2-enyl)-6-oxo-1,6-dihydropyridine-2-carbonitrile (Avalos, et al., 2000; Clyde-Watson, et al., 1998; Yuan and Yu, 2014).

The geometries of the transition states involved in the [4+2] cycloaddition reactions of the TFE with furan, thiophene, and selenophene are presented in Fig. 4. Studying the lengths of the formed bonds in the transition state indicates that these reactions follow asynchronous processes. The lengths, at the regioisomeric transition states, between the carbon atom with two fluorine atoms and carbon atom in heterocycles are
TABLE I

The Degree of Asynchronicity, $\Delta \mathrm{D}$, at the Transition States

\begin{tabular}{lc}
\hline \hline Transition states & $\Delta \mathrm{d}$ \\
\hline TS2a & 0.202 \\
TS2b & 0.214 \\
TS3a & 0.269 \\
TS3b & 0.248 \\
TS4a & 0.305 \\
TS4b & 0.260 \\
\hline
\end{tabular}

shorter. Consequently, the sigma-sigma bond formation at the more electrophilic conjugated positions is more advanced than the other.

The degree of a synchronicity $(\Delta \mathrm{d})$ can be calculated by considering the lengths difference between the two forming bonds at the transition states. The values of $\Delta \mathrm{d}$ are reported in Table I. The analysis of $\Delta \mathrm{d}$ shows that the endo transition states are more asynchronous than the exo transition states when TFE reacts with thiophene and selenophene. However, in the case of TFE with furan the degree of asynchronicity of exo transition state is more than the endo transition state. It can be noted from the table that the $\Delta \mathrm{d}$ increases, for both endo and exo transition states, on proceeding from furan, through thiophene, and on to selenophene. It can be concluded that the presence of two fluorine atoms with high electronegativity on one side of the TFE leads to a more asynchronous transition states.

MP2 and CCSD(T) methods, using the same basis set, were used to calculate the reaction energies for the title reactions and the results were compared with B3LYP functional. Table II shows the reaction energies for each reaction at three different levels of theory. The MP2 and $\operatorname{CCSD}(\mathrm{T})$ methods 
both produce more negative reaction energies than B3LYP functional. It is worth to realize that the exo path for all reactions is more exothermic than the endo path at all levels of theory. This confirms that exo-adducts are more favorable than endo-adducts. In addition, the reaction energy decreases on proceeding from furan, through thiophene, and onto selenophene. The relative energies for products and transition states at B3LYP/6-31G(d) and MP2/6-31G(d) levels of theory are listed in Table III.

HOMO and LUMO energies in electron volt $(\mathrm{eV})$ at B3LYP/6-31G(d) level of theory are computed for reactants and products, as shown in Table IV. The MO for the most stable exo-adducts are shown in Fig. 5. As shown form the results, the energy gap decrease on proceeding from furan to selenophene. It is worth to realize that the energy gap for exo-adducts is higher than the endo-adducts which indicates the stability of the exo-adducts.

The thermodynamic parameters for the [4+2] cycloaddition reactions of TEF with furan, thiophene, and selenophene in the gas phase at $1 \mathrm{~atm}$ and $298.15 \mathrm{~K}$ with B3LYP functional and MP2 method are listed in Table V. The activation enthalpies for these reactions range from 24.96 to $34.15 \mathrm{kcal} / \mathrm{mol}$ using B3LYP functional, whereas these values decrease when MP2 method is used. The activation enthalpies, as shown from

TABLE II

REACTION ENERGy (IN KCAL/MOL) FOR EACH REACTION AT B3LYP/6-31G(D), MP2/6-31G(D) AND CCSD(T)/6-31G(D) LEVELS OF THEORY

\begin{tabular}{lccc}
\hline \hline Reactions & \multicolumn{3}{c}{ Reaction energy (kcal/mol) } \\
\cline { 2 - 4 } & B3LYP & MP2 & CCSD(T) \\
\hline TFE+furan (endo) & -13.3 & -24.44 & -28.51 \\
TFE+furan (exo) & -14.5 & -25.88 & -30.04 \\
TFE+thiophene (endo) & -12.3 & -24.89 & -28.25 \\
TFE+thiophene (exo) & -13.14 & -26.03 & -29.27 \\
TFE+selenophene (endo) & -20.17 & -33.38 & -36.54 \\
TFE+selenophene (exo) & -20.88 & -34.38 & -37.46 \\
\hline \hline
\end{tabular}

TABLE III

Relative Energies ( $\Delta$ E) In (KCAL/MOL) COMPuted AT B3LYP/6-31G(D) AND MP2/6-31G(D) LEVELS OF THEORY

\begin{tabular}{lcc}
\hline \hline Structure & $\Delta \mathrm{E}(\mathrm{B} 3 \mathrm{LYP})$ & $\Delta \mathrm{E}(\mathrm{MP})$ \\
\hline TFE+furan & 0.00 & \\
Reactants & -13.29 & 0.00 \\
P2a & 27.00 & -24.44 \\
TS2a & -14.50 & 19.80 \\
P2b & 25.54 & -25.88 \\
TS2b & & 18.12 \\
TFE+thiophene & 0.00 & \\
Reactants & -12.30 & 0.00 \\
P3a & 34.66 & -24.89 \\
TS3a & -13.14 & 25.24 \\
P3b & 34.15 & -26.03 \\
TS3b & & 24.51 \\
TFE+selenophene & 0.00 & \\
Reactants & -20.17 & 0.00 \\
P4a & 30.59 & -33.38 \\
TS4a & -20.88 & 20.54 \\
P4b & 30.50 & -34.37 \\
TS4b & & 20.27 \\
\hline \hline
\end{tabular}

the table, for the exo paths, are lower compared to the endo paths. All products are entropically disfavored. The values of Gibbs free energy for all exo-adducts are negative values, which refer to spontaneous reactions. The heat of formation for all products is negative which indicates the stability of these products. The values of Gibbs free energy for products $2 \mathrm{a}$ and $3 \mathrm{a}$ were found to be 0.56 and $1.76 \mathrm{kcal} / \mathrm{mol}$ and these values become more negative when MP2 method is used. However, the Gibbs free energy of $4 \mathrm{a}$ and $4 \mathrm{~b}$ was -6.02 and $-6.74 \mathrm{kcal} / \mathrm{mol}$, respectively. These negative values indicate the spontaneity of reactions for both exo- and endo-adducts. Based on the observed data of thermodynamic parameters, it can be concluded that the exo reaction paths are formed faster and have lower heat of formation, thus the exo reaction paths are preferred thermodynamically as well as kinetically.

Products branching ratios (BR) were estimated using the method previously used by McFarland, et al., 1974 for all reactions to obtain the product percent yield. The BR for all possible products are collected in Table VI. As shown in Table VI, the exo-adducts for all reactions had a higher percent yield than endo-adducts. Similar results were obtained experimentally by Richard, et al. for the reaction of TFE with furan (Chambers, et al., 2000). The percent yield of endo-adducts increases only slightly on proceeding from

TABLE IV

HOMO ENERGIEs, LUMO ENERGIES, AND ENERGY GAP (IN EV UNIT) FOR Reactants and Products at B3LyP/6-31G(D) Level of Theory

\begin{tabular}{lccc}
\hline \hline Structure & HOMO & LUMO & Energy gap \\
\hline TFE & -6.92 & 0.73 & 7.65 \\
Furan & -6.11 & 0.54 & 6.64 \\
Thiophene & -6.34 & -0.21 & 6.13 \\
Selenophene & -6.31 & -0.33 & 5.97 \\
P2a & -7.30 & -0.48 & 6.81 \\
P2b & -7.24 & -0.37 & 6.88 \\
P3a & -6.42 & -1.13 & 5.30 \\
P3b & -6.55 & -1.11 & 5.44 \\
P4a & -5.99 & -1.46 & 4.54 \\
P4b & -6.15 & -1.48 & 4.67 \\
\hline \hline
\end{tabular}

HOMO: Highest occupied molecular orbital, LUMO: Lowest unoccupied molecular orbital

TABLE V

Thermodynamic Parameters for Transition States and Products at B3LYP/6-31G(D) AND MP2/6-31G(D) LEVELS OF THEORY IN (KCAL/MOLE) FOR $\Delta \mathrm{H}$ AND $\Delta \mathrm{G}$ AND IN (CAL/MOL.K) FOR $\Delta \mathrm{S}$

\begin{tabular}{lccccccc}
\hline \hline Structure & \multicolumn{3}{c}{ B3LYP } & & \multicolumn{3}{c}{ MP2 } \\
\cline { 2 - 4 } \cline { 7 - 8 } & $\Delta \mathrm{H}$ & $\Delta \mathrm{G}$ & $\Delta \mathrm{S}$ & & $\Delta \mathrm{H}$ & $\Delta \mathrm{G}$ & $\Delta \mathrm{S}$ \\
\hline P2a & -14.47 & 0.56 & -50.40 & & -25.72 & -10.53 & -50.96 \\
P2b & -15.68 & -0.66 & -50.38 & & -27.16 & -11.97 & -50.96 \\
P3a & -13.42 & 1.76 & -50.92 & & -26.11 & -10.73 & -51.58 \\
P3b & -14.25 & 0.93 & -50.92 & & -27.25 & -11.87 & -51.58 \\
P4a & -21.21 & -6.02 & -50.98 & & -34.52 & -19.14 & -51.56 \\
P4b & -21.91 & -6.74 & -50.87 & -35.50 & -20.15 & -51.48 \\
TS2a & 26.42 & 40.02 & -45.61 & 19.10 & 32.96 & -46.48 \\
TS2b & 24.96 & 38.54 & -45.53 & & 17.42 & 31.27 & -46.44 \\
TS3a & 34.16 & 47.88 & -46.03 & & 24.63 & 38.62 & -46.93 \\
TS3b & 33.63 & 47.36 & -46.04 & 23.89 & 37.88 & -46.94 \\
TS4a & 30.14 & 43.91 & -46.22 & & 19.99 & 34.03 & -47.08 \\
TS4b & 30.05 & 43.81 & -46.15 & & 19.71 & 33.73 & -47.02 \\
\hline \hline
\end{tabular}




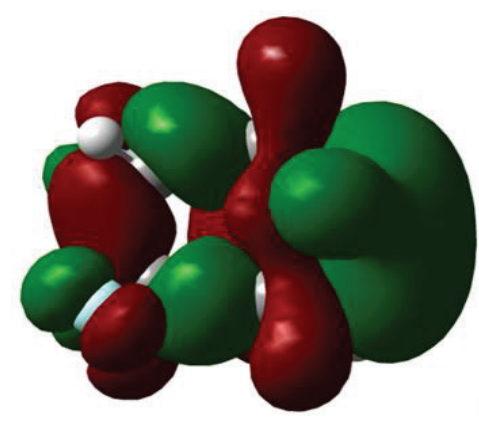

HOMO

$-7.30 \mathrm{eV}$

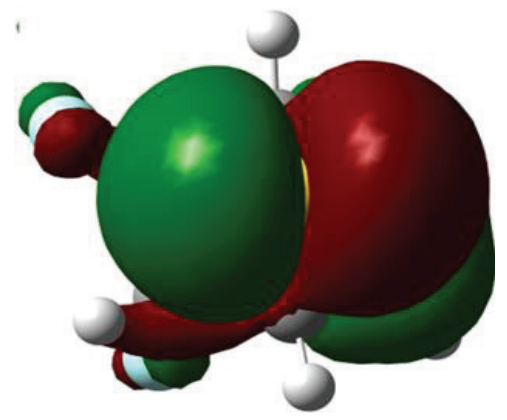

HOMO

$-6.55 \mathrm{eV}$

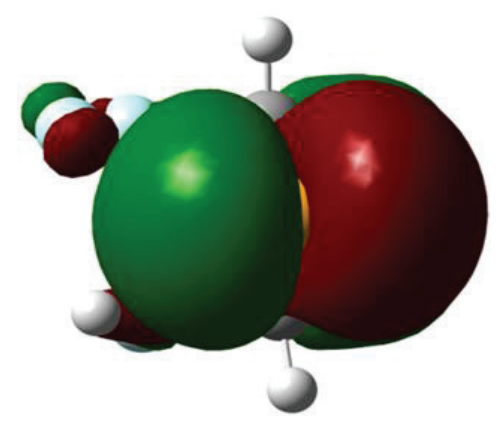

HOMO

$-6.15 \mathrm{eV}$

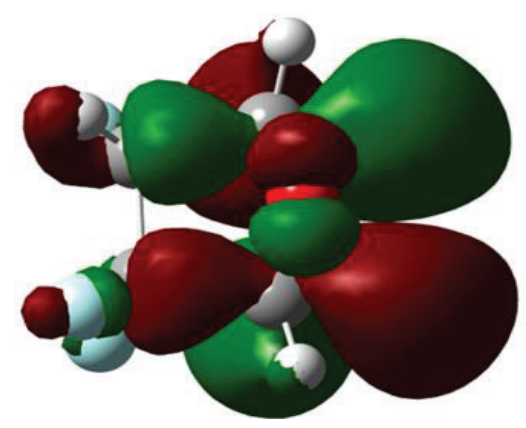

P2b

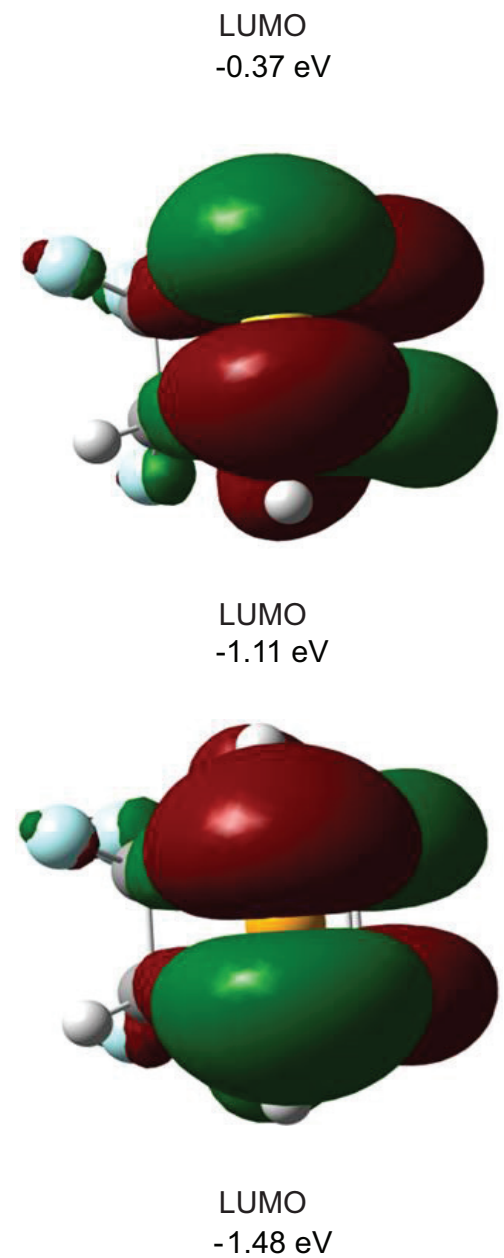

Fig. 5. B3LYP highest occupied molecular orbital and lowest unoccupied molecular orbital of the exo-adducts for all reactions at B3LYP/6-31G(d) level of theory.

TABLE VI

Product Branching Ratios and Percent Yield for EXo- AND ENDOADDUCTS

\begin{tabular}{lcc}
\hline \hline Products & Branching ratios & \% Yield \\
\hline P2a & 0.114 & 11.40 \\
P2b & 0.886 & 88.60 \\
P3a & 0.1963 & 19.63 \\
P3b & 0.8037 & 80.37 \\
P4a & 0.2283 & 22.83 \\
P4b & 0.7717 & 77.17 \\
\hline \hline
\end{tabular}

furan, through thiophene, and on to selenophene: About $11.40 \%, 19.63 \%$, and $22.83 \%$, respectively. However, the percent yield of exo-adducts decreases on proceeding from furan, through thiophene, and on to selenophene: About $88.60 \%, 80.37 \%$, and $77.17 \%$, respectively.

The global reactivity indices defined within the conceptual DFT is a powerful tool to study the reactivity in polar cycloaddition reactions. The static global properties, namely, chemical hardness $(\eta)$, global nucleophilicity $(\mathrm{N})$, global electrophilicity $(\omega)$, and electronic chemical potential $(\mu)$ for the reactants, TFE, furan, thiophene, and selenophene are listed in Table VII.

The electronic chemical potential $(\mu)$ of TFE, $(\mu=-3.10 \mathrm{eV})$, is lower than furan, $(\mu=-2.79 \mathrm{eV})$, indicating thereby that 
TABLE VII

The Chemical Hardness ( $\eta$, Electronic Chemical Potential $(\mu)$, Global Electrophilicity ( $\omega$ ), AND Global Nucleophilicity (N) FOR Trifluoroethylene, Furan, Thiophene, and Selenophene in Electron VOLT

\begin{tabular}{lcccc}
\hline \hline Reactant & $\eta$ & $\mu$ & $\omega$ & $\mathrm{N}$ \\
\hline TFE & 7.65 & -3.10 & 0.63 & 1.86 \\
Furan & 6.64 & -2.79 & 0.58 & 2.68 \\
Thiophene & 6.13 & -3.27 & 0.87 & 2.45 \\
Selenophene & 5.97 & -3.32 & 0.92 & 2.48 \\
\hline \hline
\end{tabular}

the net charge will be from the furan to the electron-deficient component, TFE. However, the electronic chemical potential of TFE is higher than thiophene $(\mu=-3.27 \mathrm{eV})$ and selenophene $(\mu=-3.23 \mathrm{eV})$ indicating that the net charge transfer will be from TEF to the thiophene and selenophene.

The power of electrophilicity for thiophene and selenophene is 0.87 and $0.92 \mathrm{eV}$, respectively, falls in the range of moderate electrophiles, whereas the for TFE and furan are 0.63 and $0.58 \mathrm{eV}$, respectively, falls in the range of marginal electrophiles within the $\omega$ scale (Domingo, et al., 2002). The electrophilicity power increases on proceeding from furan, through thiophene, and onto selenophene. Conversely, the power of nucleophilicity $(\mathrm{N})$ decreases slightly on proceeding from furan, through selenophene, and onto thiophene: About 2.68, 2.48, and $2.45 \mathrm{eV}$, respectively.

\section{CONCLUSIONS}

The B3LYP/6-31G(d) method was used to study the [4+2] cycloaddition reaction of TFE with furan, thiophene, and selenophene. The thermodynamic parameters associated with the formation of exo and endo stereoisomers in the gas phase were analyzed. These reactions are taking place through a concerted mechanism. It is observed that, on comparing the energetic results, the reaction paths leading to exo-adducts are thermodynamically and kinetically more favorable than endo-adducts. MP2 and $\operatorname{CCSD}(\mathrm{T})$ methods, using the same basis set, were used to compute the reaction energies and produced more negative reaction energies than B3LYP/6$31 \mathrm{G}(\mathrm{d})$ method. The percent yield of the exo-adducts is higher than the endo-adducts using the analysis of BR. This percent decreased on proceeding from furan to selenophene. The analysis of frontier MO indicates that the exo-adducts have larger energy gap than the endo-adducts and this indicates the stability of exo-adducts.

\section{ACKNOWLEDGMENT}

We would like to acknowledge the Department of Chemistry, Faculty of Science at University of Zakho and Department of Chemistry, College of Education at Salahaddin University.

\section{REFERENCES}

Avalos, M., Babiano, R., Bravo, J.L., Cintas, P., Jiménez, J.L., Palacios, J.C. and Silva, M.A., 2000, Understanding diastereofacial selection in carbohydrate- based domino cycloadditions: Semiempirical and DFT calculations. Chemistry A European Journal, 6(2), pp.267-77.

Baum, K., Archibald, T.G., Tzeng, D., Gilardi, R., Flippen-Anderson, J.L. and George, C., 1991. Synthesis and properties of 1,2-difluorodinitroethylene. The Journal of Organic Chemistry, 56(2), pp.537-539.

Chambers, R.D., Gilbert, A.F. ad Powell, R.L., 2000. Cycloaddition reactions of furan derivatives with trifluoroethene. Journal of Fluorine Chemistry, 104(2), pp.233-237.

Clyde-Watson, Z., Vidal-Ferran, A., J. Twyman, L.J., Walter, C.J., McCallien, D.W.J., Fanni, S., Bampos, N., Wylie, R.S. and Sanders, J.K.M., 1998. Reversing the stereochemistry of a diels alder reaction: Use of metalloporphyrin oligomers to control transition state stability. New Journal of Chemistry, 22(5), pp.493-502.

Cooley, J.H. and Williams, R.V., 1997. Endo and exo-stereochemistry in the diels-alder reaction: Kinetic versus thermodynamic control. Journal of Chemical Education, 74(5), p.582.

Cossío, F.P., Morao, I., Jiao, H. and Schleyer, P.V.R., 1999. In-plane aromaticity in 1,3-dipolar cycloadditions. Solvent effects, selectivity, and nucleus-independent chemical shifts. Journal of the American Chemical Society, 121(28), pp.67376746

Ditchfield, R., Hehre, W.J. and Pople, J.A., 1971. Self-consistent molecularorbital methods. IX. An extended gaussian-type basis for molecular-orbital studies of organic molecules. The Journal of Chemical Physics, 54(2), pp.724728.

Domingo, L.R., Asensio, A. and Arroyo, P., 2002. Density functional theory study of the lewis acid-catalyzed diels alder reaction of nitroalkenes with vinyl ethers using aluminum derivatives. Journal of Physical Organic Chemistry, 15(9), pp.660-666.

Domingo, L.R., Aurell, M.J. and Pérez, P., 2014. The mechanism of ionic diels alder reactions. A DFT study of the oxa-Povarov reaction. RSC Advances, 4(32), pp.16567-16577.

Domingo, L.R., Aurell, M.J., Pérez, P. and Contreras, R., 2002. Quantitative characterization of the global electrophilicity power of common diene/dienophile pairs in diels alder reactions. Tetrahedron, 58(22), pp.4417-4423.

Domingo, L.R., Chamorro, E. and Pérez, P., 2008. Understanding the reactivity of captodative ethylenes in polar cycloaddition reactions. A theoretical study. The Journal of Organic Chemistry, 73(12), pp.4615-4624.

Essers, M., Mück-Lichtenfeld, C. and Haufe, G., 2002. Diastereoselective diels alder reactions of $\alpha$-fluorinated $\alpha, \beta$-unsaturated carbonyl compounds: Chemical consequences of fluorine substitution. The Journal of Organic Chemistry, 67(14), pp.4715-4721.

Fernández, I. and Bickelhaupt, F.M., 2014. Origin of the "endo rule" in DielsAlder reactions. Journal of Computational Chemistry, 35(5), pp.371-376.

Foster, R.W., Benhamou, L., Porter, M.J., Bučar, D.K., Hailes, H.C., Tame, C.J. and Sheppard, T.D., 2015. Irreversible endo-selective Diels-Alder reactions of substituted alkoxyfurans: A general synthesis of endo-cantharimides. Chemistry A European Journal, 21(16), pp.6107-6114.

Frisch, M.J., Trucks, G.W., Schlegel, H.B., Scuseria, G.E., Robb, M.A., Cheeseman, J.R., Scalmani, G., Barone, V., Petersson, G.A., Nakatsuji, H., Li, X., Caricato, M., Marenich, A.V., Bloino, J., Janesko, B.G., Gomperts, R., Mennucci, B., Hratchian, H.P., Ortiz, J.V., Izmaylov, A.F., Sonnenberg, J.L., Williams-Young, D., Ding, F., Lipparini, F., Egidi, F., Goings, J., Peng, B., Petrone, A., Henderson, T., Ranasinghe, D., Zakrzewski, V.G., Gao, J., Rega, N., Zheng, G., Liang, W., Hada, M., Ehara, M., Toyota, K., Fukuda, R., Hasegawa, J., Ishida, M., Nakajima, T., Honda, Y., Kitao, O., Nakai, H., Vreven, T., Throssell, K., Montgomery Jr., J.A., Peralta, J.E., Ogliaro, F., Bearpark, M.J., Heyd, J.J., Brothers, E.N., Kudin, K.N., Staroverov, V.N., Keith, T.A., Kobayashi, R., Normand, J., Raghavachari, K., Rendell, A.P., Burant, J.C., Iyengar, S.S., Tomasi, J., Cossi, M., Millam, J.M., Klene, M., Adamo, C., Cammi, R., Ochterski, J.W., Martin, R.L., Morokuma, K., Farkas, O., Foresman, J.B. and Fox, D.J., 2009, Gaussian 09 B.01, Wallingford, CT. 
Fukui, K., 1970. Formulation of the reaction coordinate. The Journal of Physical Chemistry, 74(23), pp.4161-4163.

Gregoritza, M. and Brandl, F.P., 2015. The Diels-Alder reaction: A powerful tool for the design of drug delivery systems and biomaterials. European Journal of Pharmaceutics and Biopharmaceutics, 97, pp.438-453.

Ho, G.M., Huang, C.J., Li, E.Y.T., Hsu, S.K., Wu, T., Zulueta, M.M.L., Wu, K.B. and Hung, S.C., 2016, Unconventional exo selectivity in thermal normal-electron-demand Diels-Alder reactions. Scientific Reports, 6, p.35147.

Hoffmann, R. and Woodward, R.B., 1968. Conservation of orbital symmetry. Accounts of Chemical Research, 1(1), pp.17-22.

Houk, K.N., Lin, Y.T. and Brown, F.K., 1986. Evidence for the concerted mechanism of the Diels-Alder reaction of butadiene with ethylene. Journal of the American Chemical Society, 108(3), pp.554-556.

Ito, H., Saito, A. and Taguchi, T., 1998. Asymmetric Diels-Alder reactions of 2-fluoroacrylic acid derivatives. Part 1: The construction of fluorine substituted chiral tertiary carbon. Tetrahedron: Asymmetry, 9(11), pp.1979-1987.

Ito, H., Saito, A., Kakuuchi, A. and Taguchi, T., 1999. Synthesis of 2-fluoro analog of 6-aminonorbornane-2,6-dicarboxylic acid: A conformationally rigid glutamic acid derivative. Tetrahedron, 55(44), pp.12741-12750.

Khabashesku, V.N., Kudin, K.N. and Margrave, J.L., 2001. Density functional theoretical studies of [2+2] cycloaddition of simple transient silenes and germenes to ethylene, formaldehyde, and thioformaldehyde, and vibrational analysis of spectra of reactants and cyclic products. Russian Chemical Bulletin, 50(1), pp.20-28.

Kohn, W. and Sham, L.J., 1965. Self-consistent equations including exchange and correlation effects. Physical Review, 140(4A), p.A1133.

Lautens, M. and Edwards, L.G., 1989. Stereoselectivity in the homo Diels-Alder reaction. Tetrahedron Letters, 30(49), pp.6813-6816.

Lee, C., Yang, W. and Parr, R.G., 1988. Development of the Colle-Salvetti correlation-energy formula into a functional of the electron density. Physical Review B, 37(2), pp.785-789.

Legault, C., 2009, CYLview 1.0. Université de Sherbrooke, Sherbrooke.

Lemal, D.M., 2017. Pathways for concerted [2+2] cycloaddition to cumulenes. The Journal of Organic Chemistry, 82(24), pp.13012-13019.

Leroy, J., Molines, H. and Wakselman, C., 1987. Facile synthesis of ethyl 3,3-difluoroacrylate from dibromodifluoromethane and Diels-Alder cycloaddition with furan. The Journal of Organic Chemistry, 52(2), pp.290-292.

Levandowski, B.J., Hamlin, T.A., Helgeson, R.C., Bickelhaupt, F.M. and Houk, K., 2018. Origins of the endo and exo selectivities in cyclopropenone, iminocyclopropene, and triafulvene Diels-Alder cycloadditions. The Journal of Organic Chemistry, 83(6), pp.3164-3170.

Liu, J., Niwayama, S., You, Y. and Houk, K.N., 1998. Theoretical prediction and experimental tests of conformational switches in transition states of Diels-Alder and 1,3-dipolar cycloadditions to enol ethers. The Journal of Organic Chemistry, 63(4), pp.1064-1073.

Lozynskyi, A., Zimenkovsky, B., Karkhut, A., Polovkovych, S., Gzella, A.K. and Lesyk, R., 2016. Application of the 2(5H)furanone motif in the synthesis of new thiopyrano[2,3-d]thiazoles via the hetero-Diels-Alder reaction and related tandem processes. Tetrahedron Letters, 57(30), pp.3318-3321.
McFarland, M., Albritton, D.L., Fehsenfeld, F.C., Ferguson, E.E. and Schmeltekopf, A.L., 1974. Energy dependence and branching ratio of the $\mathrm{N} 2^{+}+$O reaction. Journal of Geophysical Research (1896-1977), 79(19), pp.2925-2926.

Nickon, A., Kwasnik, H.R., Mathew, C.T., Swartz, T.D., Williams, R.O. and DiGiorgio, J.B., 1978. Synthesis and structure proof of C-2 and C-4 monofunctionalized brexanes and brendanes. The Journal of Organic Chemistry, 43(20), pp.3904-3916.

Nicolaou, K.C., Snyder, S.A., Montagnon, T. and Vassilikogiannakis, G., 2002. The Diels-Alder reaction in total synthesis. Angewandte Chemie International Edition, 41(10), pp.1668-1698.

Parr, R.G. and Pearson, R.G., 1983. Absolute hardness: Companion parameter to absolute electronegativity. Journal of the American Chemical Society, 105(26), pp.7512-7516.

Parr, R.G. and Weitao, Y., 1989. Density-Functional Theory of Atoms and Molecules. Oxford University Press, Oxford.

Parr, R.G. and Weitao, Y., 1994. Density-Functional Theory of Atoms and Molecules. Oxford University Press, Oxford.

Parr, R.G., Szentpály, L.V. and Liu, S., 1999. Electrophilicity index. Journal of the American Chemical Society, 121(9), pp.1922-1924.

Pavelyev, R.S., Vafina, R.M., Lodochnikova, O.A., Galiullina, A.S., Romanova, E.I., Balakin, K.V. and Shtyrlin, Y.G., 2016. Stereochemistry of hexachlorocyclopentadiene [4+2]-cycloaddition to 2-substituted 4,7-dihydro1,3-dioxepins. Tetrahedron Letters, 57(35), pp.3902-3907.

Rivero, U., Meuwly, M. and Willitsch, S., 2017a. A computational study of the Diels-Alder reactions between 2,3-dibromo-1,3-butadiene and maleic anhydride. Chemical Physics Letters, 683, pp.598-605.

Rivero, U., Meuwly, M. and Willitsch, S., 2017b. A computational study of the Diels-Alder reactions between 2, 3-dibromo-1, 3-butadiene and maleic anhydride. Chemical Physics Letters, 683, pp.598-605.

Rulíšek, L., Šebek, P., Havlas, Z., Hrabal, R., Čapek, P. and Svatoš, A., 2005. An experimental and theoretical study of stereoselectivity of Furan-Maleic anhydride and Furan-Maleimide Diels-Alder reactions. The Journal of Organic Chemistry, 70(16), pp.6295-6302.

Silva, M.A.A. and Goodman, J.M., 2002. Nitrone cyclisations: The development of a semi-quantitative model from ab initio calculations. Tetrahedron, 58(19), pp.3667-3671.

Szalai, M.L., McGrath, D.V., Wheeler, D.R., Zifer, T. and McElhanon, J.R., 2007. Dendrimers based on thermally reversible Furan-Maleimide Diels-Alder adducts. Macromolecules, 40(4), pp.818-823.

Teixeira, F., Rodríguez-Borges, J.E., Melo, A. and Cordeiro, M.N.D., 2009. Stereoselectivity of the aza-Diels-Alder reaction between cyclopentadiene and protonated phenylethylimine derived from glyoxylates. A density functional theory study. Chemical Physics Letters, 477(1), pp.60-64.

Woodward, R.B. and Katz, T.J., 1959. The mechanism of the Diels-Alder reaction. Tetrahedron, 5(1), pp.70-89.

Yuan, L. and Yu, H.T., 2014. Cascade cyclization of 1-(2-yl-3-phenylprop-2enyl)-6-oxo-1,6-dihydropyridine-2-carbonitrile radical: Mechanistic insights from DFT study. Computational and Theoretical Chemistry, 1044, pp.1-9. 